\title{
Detection of genetically modified soybean and its product tou-kan by polymerase chain reaction with dual pairs of DNA primers
}

Yi-Ching Liu • Hsin-Hung Lin • Hsi-Mei Lai •

Shih-Tong Jeng

Published online: 28 September 2007

(C) Springer-Verlag 2007

Erratum to: Eur Food Res Technol (2005) 221:725-730 DOI 10.1007/s00217-005-0066-2

The original version of this article unfortunately contained a mistake. The name of the second author given was incorrectly. The correct name is: Hsin-Hung Lin.

The online version of the original article can be found under doi: 10.1007/s00217-005-0066-2.

Y.-C. Liu · H.-H. Lin · S.-T. Jeng $(\bowtie)$

Institute of Plant Biology and Department of Life Science,

Taipei 106, Taiwan, Republic of China

e-mail: stjeng@ntu.edu.tw

H.-M. Lai

Department of Agricultural Chemistry,

National Taiwan University, Taipei 106,

Taiwan, Republic of China 